\title{
The Influence of the Roll-Laminating Process on the Bonding Quality of Polymer-Coated Steel Interface
}

\author{
Jiyang Liu, Qingdong Zhang *, Boyang Zhang * and Mingyang Yu \\ School of Mechanical Engineering, University of Science and Technology, Beijing 100083, China; \\ b20170270@xs.ustb.edu.cn (J.L.); b20190253@xs.ustb.edu.cn (M.Y.) \\ * Correspondence: zhang_qd@me.ustb.edu.cn (Q.Z.); asdfaa01@foxmail.com (B.Z.)
}

check for updates

Citation: Liu, J.; Zhang, Q.; Zhang,

B.; Yu, M. The Influence of the

Roll-Laminating Process on the Bonding Quality of Polymer-Coated Steel Interface. Coatings 2021, 11, 472. https://doi.org/10.3390/

coatings11040472

Academic Editor: Nicolas Delorme

Received: 21 March 2021

Accepted: 14 April 2021

Published: 17 April 2021

Publisher's Note: MDPI stays neutral with regard to jurisdictional claims in published maps and institutional affiliations.

Copyright: (c) 2021 by the authors. Licensee MDPI, Basel, Switzerland. This article is an open access article distributed under the terms and conditions of the Creative Commons Attribution (CC BY) license (https:// creativecommons.org/licenses/by/ $4.0 /)$.

\begin{abstract}
Polymer-coated steel (PCS) is a new type of metal packaging material under development, which has better performance in saving resources, energy, and environmental protection. The lamination process has an important influence on the bonding quality of the PCS interface. PCS samples under different lamination temperatures and lamination speeds were prepared through experiments. A binding rate is defined to represent the real bonding area of the PCS interface. The micro-scratch tester and scanner are used to study the influence of the lamination process on the bonding rate and bonding strength of the PCS interface. It is proposed that the bonding rate and bonding strength of the PCS interface increases with the increase of lamination temperature and increases with the decrease of lamination speed. The PCS interface bonding rate and bonding strength are positively correlated. SEM and DSC experiments revealed the cause of bubbles on the PCS surface. It is proposed that controlling the uniformity of the TFS surface temperature can reduce the quality defects of PCS surface bubbles. Relevant research results bring guiding significance for the formation of enterprises.
\end{abstract}

Keywords: polymer-coated steel; lamination process; interface defect; lamination quality; binding rate; bonding strength

\section{Introduction}

With the gradual development of the metal packaging industry in the direction of green, energy saving, and environmental protection, more and more attention has been paid to the surface-coating technology of metal products. Polymer-coated steel (PCS), a new type of metal and non-metal layered composite strip, is mainly used in the metal packaging industry. It can replace tin plate to reduce the consumption of tin resources and increase the corrosion resistance and aesthetics of the product. At present, PCS products have been widely used in Japan, Europe and the United States. The mass popularization of PCS products is bound to be the future development trend [1-4].

PCS is prepared by roll-pressing and the hot-fusion coating process. Through a series of physical and chemical reactions such as continuous contact temperature rise, surface melting, roll bonding, hydrogen bonding, cooling and solidification, etc., the two different materials of steel and plastic are firmly bonded at the interface. The material distribution of PCS along the thickness direction is plastic, hydrated chromium oxide layer, metallic chromium layer and ordinary steel plate [5-8].

Since the PCS material was born in Japan in the 1990s, it has a development history of about 30 years. At present, the research on PCS materials in the world mainly focuses on the PCS coating process [9-11], coating quality characterization [12-14], heat transfer during the coating process [15], PCS heat treatment [16,17], PCS application [18,19], film surface modification [20-22] and so on. Komai [23] used cathodic electrolysis to prepare tin-free steel (TFS) with water and oxidation layers on the surface. The peeling experiment indicates that the presence of a hydrated chromium oxide layer on the substrate surface can increase the adhesion of the PCS interface. Suzuki [24] studied the wet adhesion characteristics of 
polymer films through cooking experiments on PCS samples and proposed two effective methods to improve interfacial adhesion: chrome-plating the steel plate and increasing the film temperature, thereby increasing the thickness of the amorphous polymer film layer. This supplements the previous results. Cho $[10,11]$ studied the influence of the coating temperature on the thickness of the polymer crystalline layer and pointed out that as the coating temperature increases, the thickness of the amorphous layer of the polymer film increases, which improves the interface bonding strength. It can be seen that the thickness of the melting layer of the polymer film during the pretreatment of the substrate surface and the coating process is an effective method to improve the bonding strength of the PCS interface. Regarding the surface treatment of substrates, most studies in the world are related to the interaction between the hydrated chromium oxide layer on the surface of TFS and the interface bonding, and the effect of the surface micro-morphology of TFS on the interface bonding is rarely mentioned. At the same time, to propose a set of indicators to accurately evaluate the quality of PCS coatings is a unified goal that has not been reached by various experts in the world.

In addition, there is still a lot of research on the mechanism that restricts the highspeed coating of metal plates in the field of PCS manufacturing process. Increasing the speed of PCS coating can increase the production efficiency of enterprises and reduce the production cost of PCS to a certain extent. In addition, experimental and theoretical studies are required for the influence of the surface morphology of the substrate chrome plate on the bonding quality of the PCS interface and the experimental basis for the hydrogen bonding of the PCS micro-interface.

From the perspective of the bonding quality of the PCS interface, this paper proposes an index that characterizes the true bonding area of the PCS interface- - the bonding rate. Through the preparation of coated iron samples, the detection of the interfacial bonding rate and interfacial bonding strength as well as the influence of the rolling coating process parameters on the quality of PCS interfacial bonding were studied. The interface bonding rate index is defined to characterize the bonding quality of the PCS interface. The scratch experiment explained the failure mechanism of the coated iron interface. Through the differential scanning calorimetry test, the reason for the bubbles on the surface of the PCS sample was studied because the surface temperature of the chrome-plated plate of the base material was not uniformly controlled, and the melting thickness of the polymer film was not uniform during the coating process. It solves the problem of film quality in PCS production and brings certain production benefits to the production of enterprises.

\section{Experiment}

\subsection{Materials}

In the lamination experiment, tin-free steel (TFS) and polyethylene terephthalate (PET) film were selected as raw materials. The laminated substrate TFS came from Shanghai Yigang Storage Co., Ltd (Yigang Storage Co., Ltd, Shanghai, China). The cladding PET film came from Shanghai Baowu Steel Co., Ltd (Shanghai Baowu Steel Co., Ltd, Shanghai, China). The TFS material has a three-layer structure in the thickness direction, which are strip steel, a metallic chromium layer, and a hydrated chromium oxide layer $[6,7,25]$, as shown in Figure 1. The thickness of the hydrated chromium oxide is $135 \mathrm{mg} / \mathrm{m}^{2}$. The total thickness of the TFS is approximately $0.18 \mathrm{~mm}$. The total thickness of the PET film is 25 um [26].

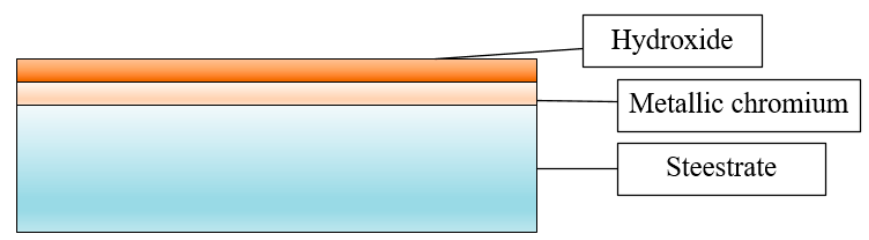

Figure 1. The surface structure of tin-free steel (TFS). 


\subsection{Laminating Experiment}

\subsubsection{Laminating Equipment}

The PCS laminating equipment, as shown in Figure 2, came from Shanghai Lianjing Electronic Technology Co., Ltd (Lianjing Electronic Technology Co., Ltd, Shanghai, China). This laminating equipment can perform single-sided laminating tests of TFS samples. The whole laminating equipment is mainly composed of three parts: console, heating part and pressing device. The heating part is a pair of electromagnetic induction heating rollers placed up and down. The main function is to heat the sample. The electromagnetic induction heating roller has a diameter of $200 \mathrm{~mm}$, a length of $1.2 \mathrm{~m}$, and a temperature control accuracy of $\pm 1 \mathrm{~K}$. The pressing device uses a set of electromagnetic induction heating rollers and silicone rubber rollers. The pressing control method is a displacement control. The displacement of the silicone roller can be manually controlled by rotating the handrail. The electromagnetic induction heating roller and the heating roller of the heating part are the same. It is prepared by covering a layer of silicone rubber with a steel core. The diameter of the steel core is $180 \mathrm{~mm}$, the thickness of the silicone layer is $20 \mathrm{~mm}$, and the length of the silicone roller is $1.2 \mathrm{~m}$. The operation of the heating part and the pressing device are controlled by a console, which sends instructions through a human-computer interaction panel to control the rotation speed and temperature of the rollers, respectively.

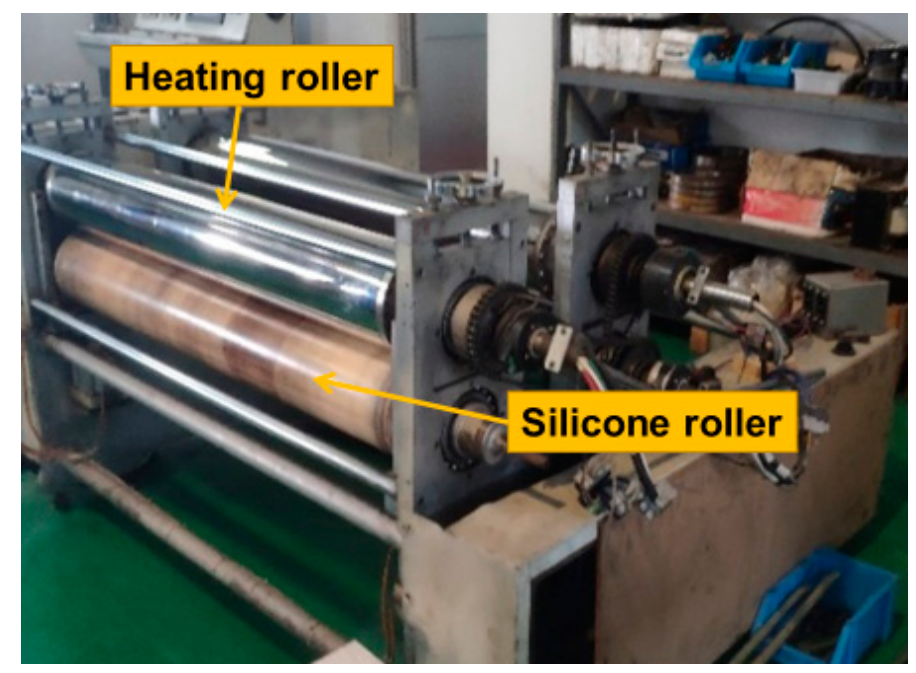

Figure 2. Lamination experimental equipment.

The principle of lamination experiment is shown in Figure 3. The laminating equipment consists of three parts: heating roller, laminating roller, and worktable. The heating roller is used to provide the temperature required during the lamination process. The worktable can control the heating temperature of the heating roller and the rotation speed of the laminating roller. The PET film is first fixed on the surface of the TFS with a hightemperature adhesive tape, and then placed in the laminating device horizontally. The PET film and TFS substrate are laminated under the double pressure of heating roller and silicone roller. 


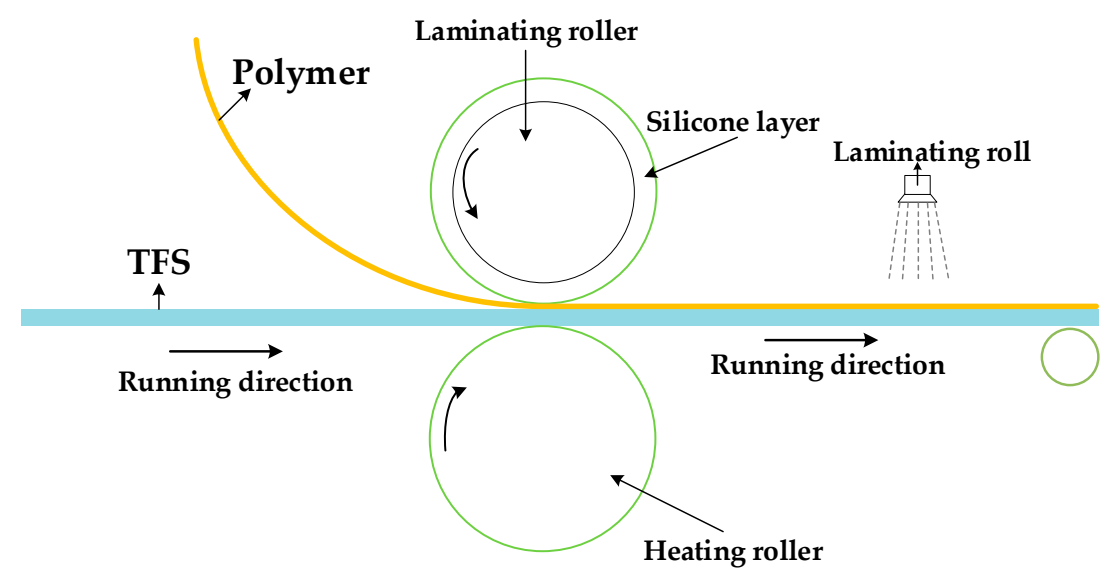

Figure 3. Schematic diagram of laminating process.

During the laminating process, the heating roller acts as a heat source to continuously provide heat to the TFS, and the TFS transfers the heat to the PET film and then to the silicone roller. The silicone roller maintains a constant temperature under the action of the cooling roller. Therefore, under the dual effects of TFS heating and silicon resin roll cooling, a temperature gradient appears inside the PET along the thickness direction, forming a partial melting. The PET film melts completely on the side near the TFS but does not melt on the side near the silicone roller. After the PET film and TFS leave the heating roller and the silicone roller, the PET film is quickly cooled with a coolant to quickly solidify the molten part of the PET, thereby avoiding recrystallization of the PET. Finally, the preparation of PCS material is completed.

\subsubsection{Experimental Scheme}

The size of the TFS sample plate is $150 \mathrm{~mm} \times 10 \mathrm{~mm} \times 0.18 \mathrm{~mm}$, and the size of the PET film is $130 \mathrm{~mm} \times 8 \mathrm{~mm}$. As the sample size is relatively small, the electromagnetic induction heating roller in the pressing device can provide enough heat for the TFS, so this experiment only uses the pressing device for lamination. By controlling the rotation speed and temperature of the electromagnetic induction heating roller, the lamination test under different temperature and speed conditions was carried out. The lamination test under different pressure conditions can be carried out by controlling the displacement of the silicone rubber roller. The experimental scheme is shown in Table 1.

Table 1. PCS experimental protocol.

\begin{tabular}{ccc}
\hline Sample Number & Temperature (K) & Laminating Speed(m/min) \\
\hline 1 & 528 & 3 \\
2 & 528 & 6 \\
3 & 528 & 9 \\
4 & 533 & 3 \\
5 & 533 & 6 \\
6 & 533 & 9 \\
7 & 538 & 3 \\
8 & 538 & 6 \\
9 & 538 & 9 \\
\hline
\end{tabular}

\subsection{Scanning Electron Microscope Experiment (SEM)}

The PCS cross-section observation experiment was carried out on a scanning electron microscope (ZEISS GeminiSEM 500, Aalen, Germany). The PCS cross-section was analyzed by line scan using the matching EDS spectrometer to obtain the $\mathrm{Fe}, \mathrm{C}, \mathrm{O}$, and $\mathrm{Cr}$ element content on the cross-section. 
The sample size was $10 \mathrm{~mm} \times 10 \mathrm{~mm} \times 0.18 \mathrm{~mm}$. Alcohol was used to clean the surface of the sample, and then the sample was placed in an ultrasonic cleaning machine for deep cleaning for $5 \mathrm{~min}$. A fan was used to dry the sample surface. It was observed where bubbles appeared at the cross section.

\subsection{Differential Scanning Calorimetry (DSC)}

The thermal performance of the PET film was performed on a differential scanning calorimeter (DSC 214 Polyma, Selb, Germany). Nitrogen was used as a protective gas. The material required for the experiment was 3 to $5 \mathrm{mg}$. The implementation scheme is shown in Figure 4. First, the temperature was raised to $573.15 \mathrm{~K}$ at a rate of $50 \mathrm{~K} / \mathrm{min}$, and the temperature was kept for five minutes to eliminate the thermal history of the material. Then it was cooled to $298.15 \mathrm{~K}$ at a rate of $10 \mathrm{~K} / \mathrm{min}$, and then heated to $573.15 \mathrm{~K}$ at $10 \mathrm{~K} / \mathrm{min}[27,28]$. The experimental results use the curve during the second heating process.

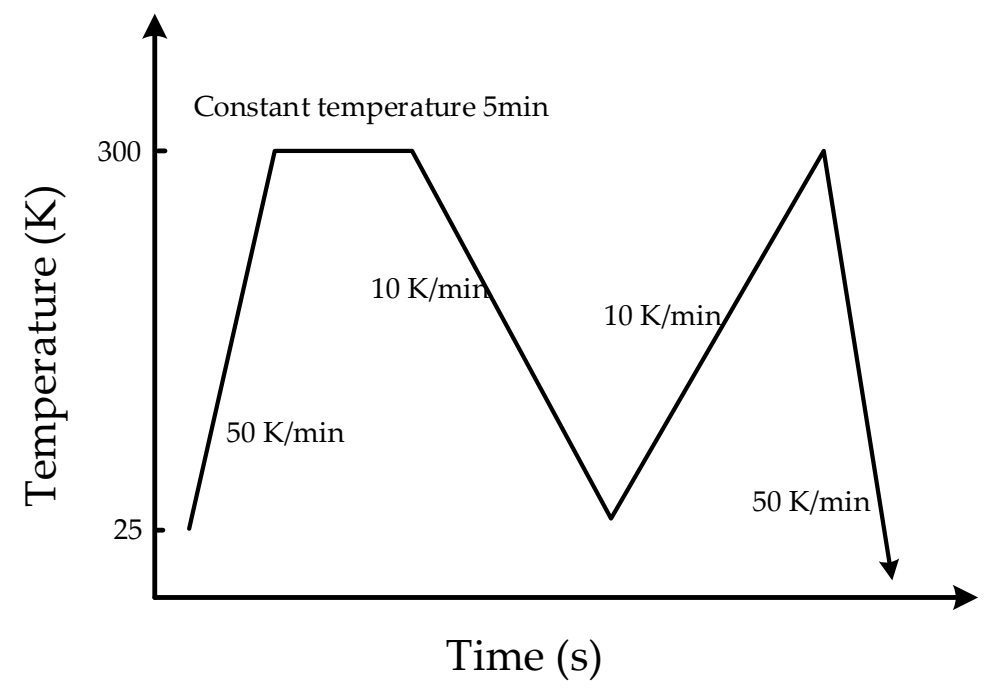

Figure 4. Differential scanning calorimetry experiment process.

\subsection{Micro-Scratch Tester}

The PCS interface bonding performance was performed on a micro-scratch tester (CSM-MCT, Peseux, Switzerland). The load setting value was $15 \mathrm{~N}$. The scratch length was $5 \mathrm{~mm}$. The test temperature was $293.15 \mathrm{~K}$, and the air humidity was $60 \%$. A round diamond indenter with a radius of $100 \mathrm{um}$ was used, and the experiment was carried out perpendicular to the sample surface in a progressive loading manner. Through online realtime observation of the contact pressure at the indenter, acoustic signals, friction, reduction depth, residual depth and other information, the interface bonding strength of different samples and the failure mechanism of the sample surface lamination were compared and analyzed. The drawing method is a straight-line drawing at a constant speed. The sample size was $10 \mathrm{~mm} \times 10 \mathrm{~mm}$. The experiment was repeated three times for each sample. The average value was taken as the experimental result.

An acoustic emission (AE) sensor was installed on the scratch meter to monitor the sound signal generated during the scratching process. Before the experiment, alcohol and an air gun were used to clean the sample, using an MH-008S ultrasonic cleaning machine to perform ultrasonic cleaning on the sample for $3 \mathrm{~min}$, and alcohol as the cleaning solvent. During the experiment, an optical microscope was used to observe the scratch morphology of the sample surface. Then, a scratch test was performed on each sample. During the experiment, the stroke speed was $5 \mathrm{~mm} / \mathrm{min}$, the loading pressure range was 0.01 to $15 \mathrm{~N}$, and the load was gradually loaded. The load increase rate was $15 \mathrm{~N} / \mathrm{min}$, the acoustic sensor sensitivity was set to 9, and the acoustic signal acquisition frequency was $30 \mathrm{~Hz}$. 


\section{Results and Discussion}

\subsection{Characterization of Interface Binding Rate}

The PCS sample prepared by the roll-pressing hot-melt coating process has irregularly shaped white spots on the surface of the coated sample, as shown in Figure 5. The existence of white spots greatly affects the aesthetics of PCS samples, and there may be problems with the quality of the film. In order to explore the formation factors of this type of defect and the influence of the process parameters on the area, the number and shape of white spots, cross-sectional observation experiments and surface image recognition of white spots were carried out using scanning electron microscopes and scanners.

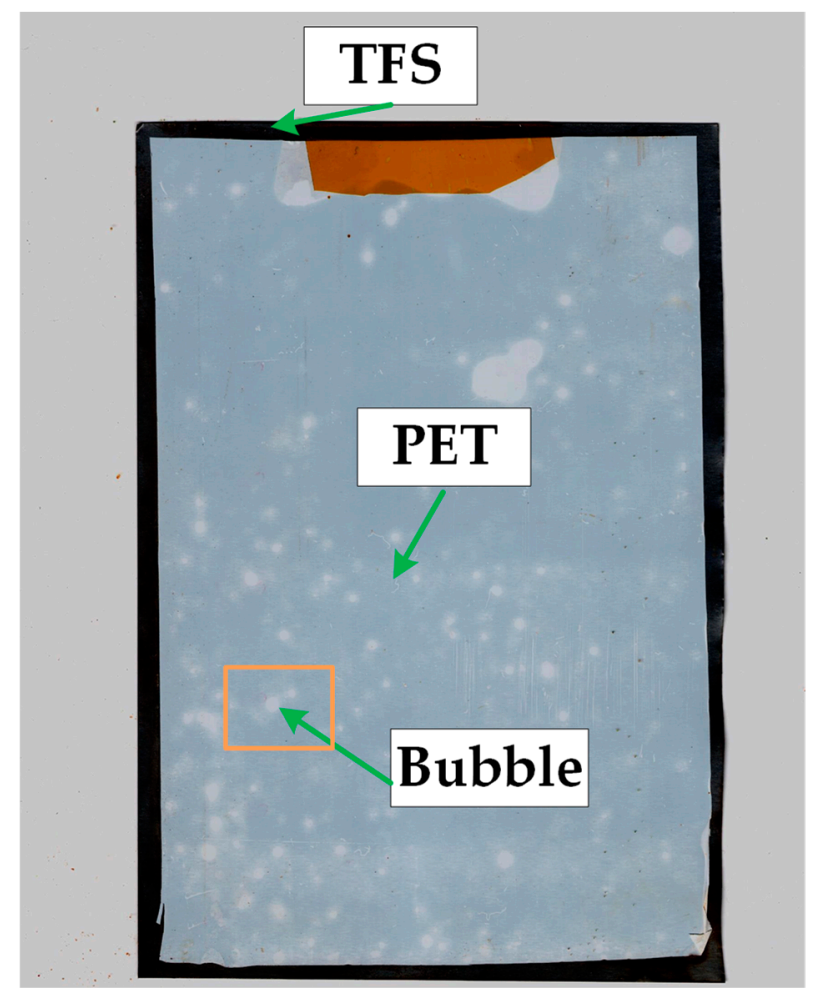

Figure 5. Polymer-coated steel sample.

Taking the PCS sample prepared with the heating roller temperature of $528 \mathrm{~K}$ and the film speed of $9 \mathrm{~m} / \mathrm{min}$ as the object, the white spots on the surface of the sample were randomly selected for SEM cross-sectional observation. As shown in Figure 6, the polymer film was separated from the chrome-plated steel strip. Using an EDS energy spectrometer to perform a line scan analysis in the direction perpendicular to the interface, it was found that there is a gap of about 40-um thickness between the polymer and the chrome-plated steel strip. The content of $\mathrm{C}, \mathrm{O}$, and Fe elements in the gap had a significant drop, indicating that there were bubbles between the polymer film and the chrome-plated steel strip. Therefore, the white spots observed on the PCS surface are due to bubbles formed by the separation of the film/iron interface. 


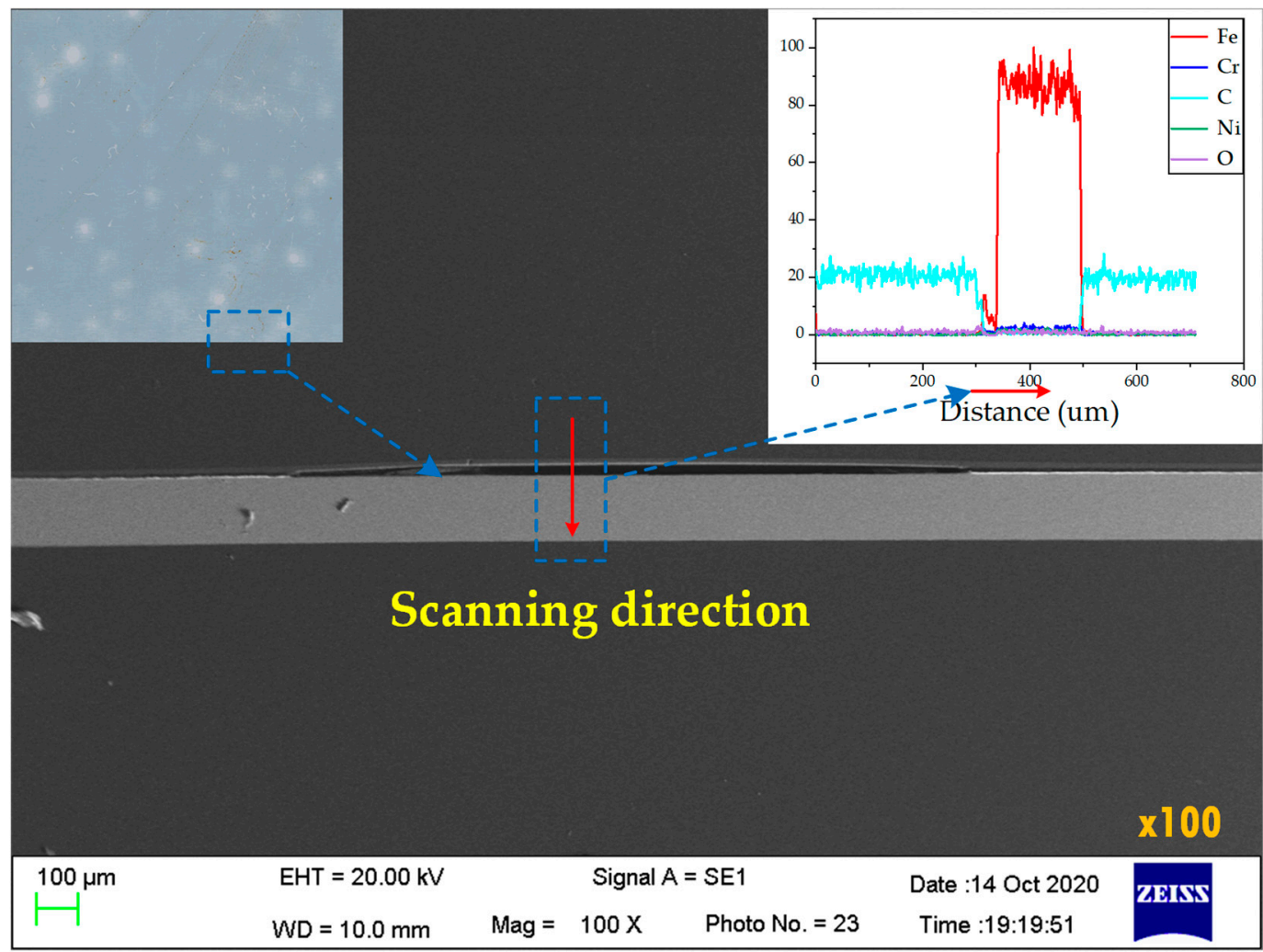

Figure 6. Scanning electron micrograph of PCS interface.

The reason for the bubble generation should be a surface defect formed by the fast coating speed during the roll-coating process, and the gas between the chrome-plated steel strip and the polymer film cannot escape in time. Bubble formation is because there is no common interface between the substrate and PET. The uneven temperature distribution on the TFS surface during the coating process can cause bubbles to appear on the PCS surface. The melting thickness of PET is mainly determined by the heating temperature of the TFS surface. When the temperature is lower than the melting point of PET, PET does not melt. Unmelted PET cannot be combined with TFS due to its inactive molecular segment structure, and bubbles are formed. So, the non-wetting behavior of the steel by molten PET is the cause of the bubble formation.

An interface bonding rate is defined to characterize the area of the "bubble" surface defect. As shown in Equation (1), $S_{\text {total }}$ is the total area of the selected area, $S_{b u b b l e}$ is the bubble area, and $r$ is the binding rate. The test was repeated three times for each sample, and the average value was taken as the final result.

$$
r=\frac{S_{\text {total }}-S_{\text {bubble }}}{S_{\text {total }}} \times 100 \%
$$

In order to study the thermal properties of the PET at the bubble, the DSC experiment was performed on the PET film at the bubble on the PCS surface and the non-bubbled PET film, and the DSC curve of the original PET before lamination was used as a comparative analysis.

During the lamination process, the PET film is partially melted in the thickness direction under the heating action of TFS and the cooling action of the laminating roll. Then, under the action of the cooling liquid, the molten part is cooled and solidified and transformed into an amorphous layer. During the heating process of the DSC experiment, when the temperature of the laminated PET film is between $310 \mathrm{~K}$ and $350 \mathrm{~K}$, the part of the amorphous layer in the PET recrystallizes and absorbs heat to produce an endothermic peak. The ideal original PET film is a crystalline polymer, and its DSC curve does not 
produce an endothermic peak. As shown in Figure 7, by comparing the size of the PET endothermic peak in the DSC experimental curve, it can be determined whether the PET film melts. It can be found that the DSC curves of PET at the bubble and PET before lamination basically overlap. It shows that the PET film does not melt at the bubble.

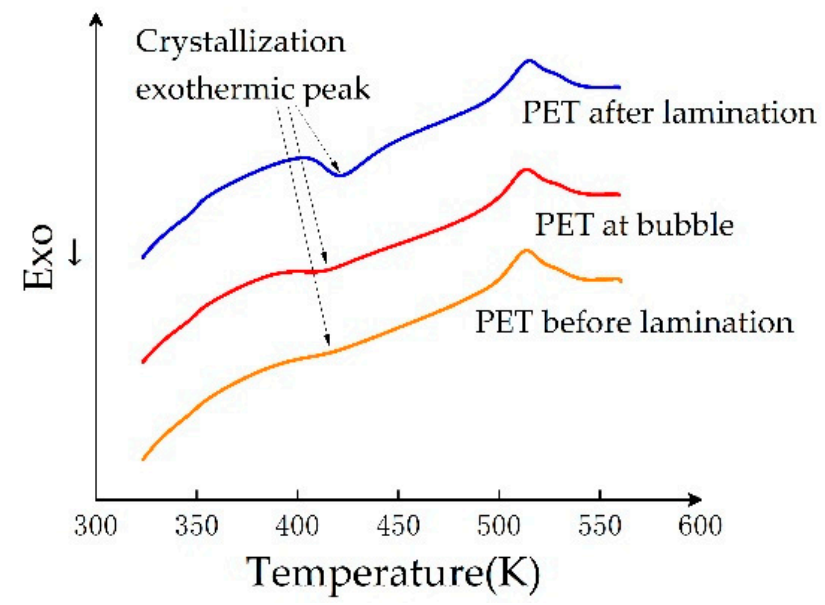

Figure 7. DSC curves of PET before lamination, at bubble, and after lamination.

A scanner was used to scan the surface images of the samples prepared under different process conditions. Use image recognition software to perform secondary processing on scanned images. Use Python language to write a picture color recognition program, calculate the area of the white part and the area of the gray part in the picture. The white part is the bubble. Calculate the interface binding rate according to formula (1). As shown in Figure 8, the picture on the left is a film-coating test, using image software to identify the surface of the sample. The blue part in the picture on the right is the part with a good combination, and the white part is the bubble. It was calculated that the area of white bubbles accounts for $37.9 \%$ of the total area. Therefore, the interface binding rate of the sample is $62.1 \%$.

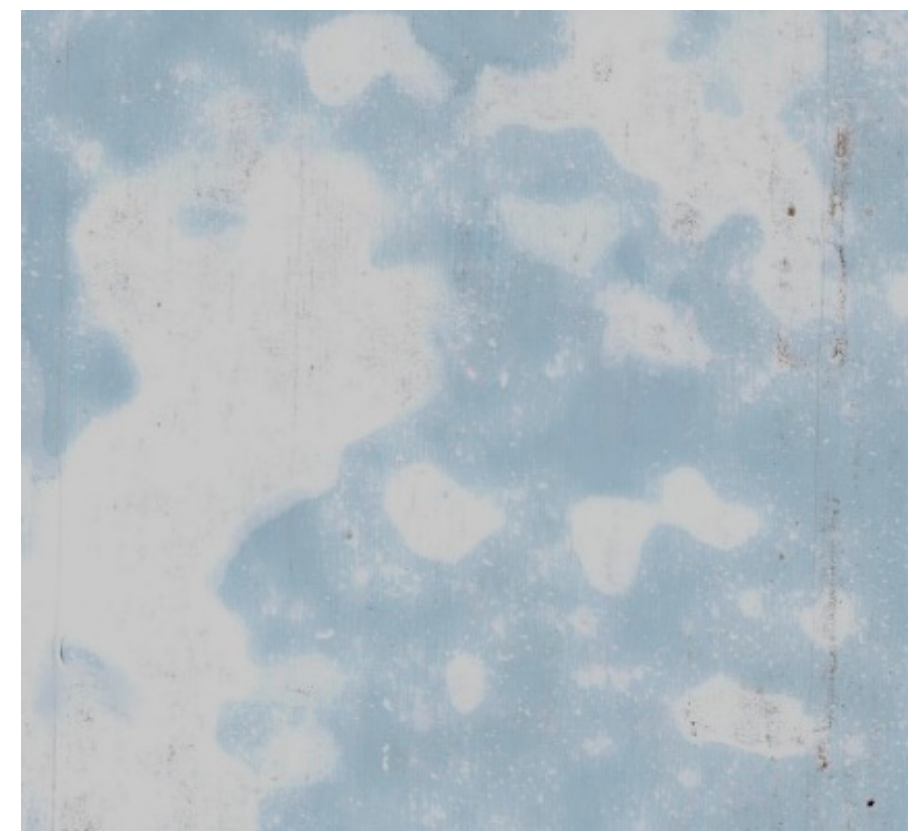

Figure 8. PCS interface binding rate. 


\subsection{Effect of Process Parameters on the Binding Rate}

As shown in the test plan in Table 1, the gap between the roll gaps is $5 \mathrm{um}$, and the surface roughness of the chrome-plated steel strip is $0.2 \mathrm{um}$. Taking the heating roller temperature and filming speed as independent variables, and the interfacial bonding rate as dependent variables, the influence of the heating roller temperature and filming speed on the PCS interface bonding rate was studied. The temperature of the heating roller was $528 \mathrm{~K}, 533 \mathrm{~K}$, and $538 \mathrm{~K}$; the film speed was $3 \mathrm{~m} / \mathrm{min}, 6 \mathrm{~m} / \mathrm{min}$, and $9 \mathrm{~m} / \mathrm{min}$. Surface scanning and image recognition processing were performed on the coated PCS samples to characterize the binding rate. Each sample was randomly selected from three different locations for testing, and finally, the average value was calculated. The size of each inspection image is $30 \mathrm{~mm} \times 30 \mathrm{~mm}$. The interface bonding ratio of sample 1 to sample 9 is shown in Figure 9, and the corresponding test parameters are shown in Table 1 test scheme.

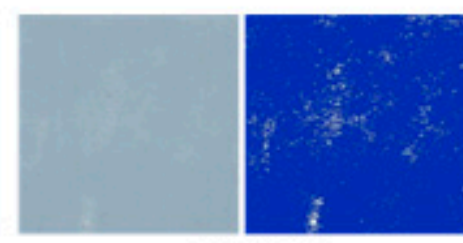

Sample 1

$(T=528 \mathrm{~K}, v=3 \mathrm{~m} / \mathrm{min}, r=97.21 \%$ )

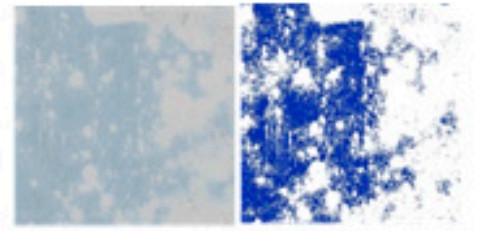

Sample 3

$(T=528 \mathrm{~K}, v=9 \mathrm{~m} / \mathrm{min}, r=36.9 \%)$

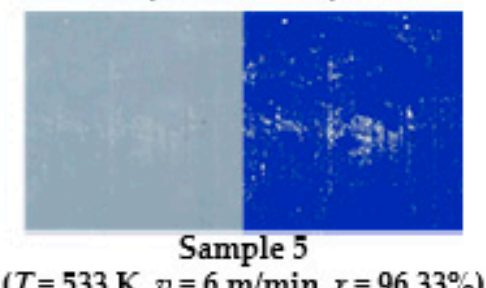

$T=533 \mathrm{~K}, v=6 \mathrm{~m} / \mathrm{min}, r=96.33 \%)$

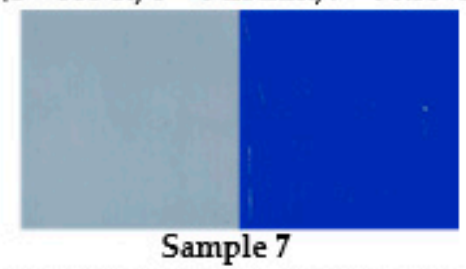

$(T=538 \mathrm{~K}, v=3 \mathrm{~m} / \mathrm{min}, r=99.90 \%)$

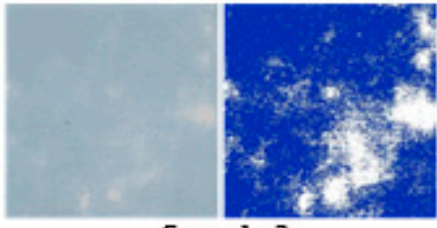

Sample 2

$(T=\mathrm{K}, v=6 \mathrm{~m} / \mathrm{min}, r=76.50 \%)$

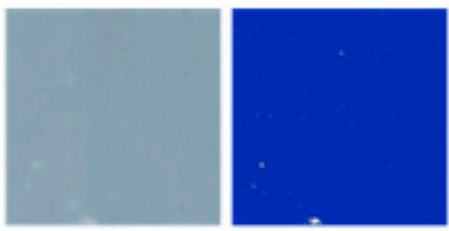

Sample 4
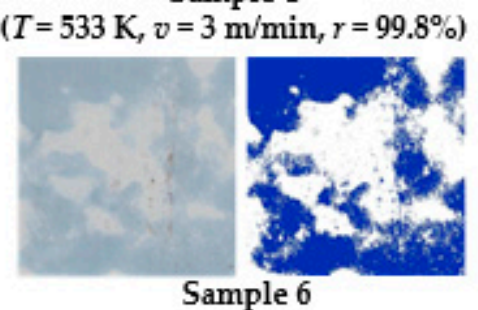

$(T=533 \mathrm{~K}, v=9 \mathrm{~m} / \mathrm{min}, r=51.30 \%)$

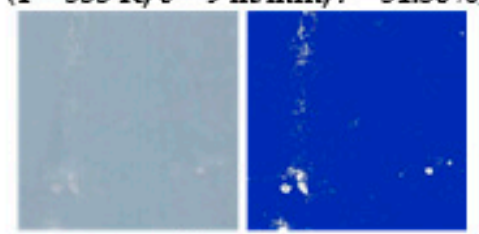

Sample 8

$(T=538 \mathrm{~K}, v=6 \mathrm{~m} / \mathrm{min}, r=98.60 \%)$

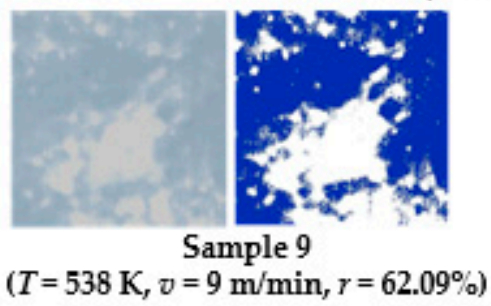

Figure 9. PCS interface binding rate $(\mathrm{r})$ under different heating temperature $(\mathrm{T})$ and speed $(\mathrm{v})$ conditions.

Samples 1 to 3 are coated samples with a heating roller temperature of $528 \mathrm{~K}$ and a coating speed of $3 \mathrm{~m} / \mathrm{min}, 6 \mathrm{~m} / \mathrm{min}$, and $9 \mathrm{~m} / \mathrm{min}$. Comparing sample 1 , sample 2 and sample 3 , it can be found that the bubbles on the surface of sample 3 are obvious, while 
the bubbles on the surface of samples 1 and 2 are relatively few. Comparing samples 4 to 6 and samples 7 to 9 , the same pattern can be found. Under the same heating roll degree and reduction conditions, as the coating speed increases, the PCS surface bonding rate gradually decreases. This is because the lower coating speed increases the PCS coating time. The increase in the coating time leads to an increase in the heat transfer time of the film iron, which increases the internal temperature of the polymer film and increases the melting of the polymer film. Thickness improves the interface bonding rate. At the same time, the reduction of the coating speed also increases the heat transfer time between the heating roller and the chrome-plated steel, making the surface temperature of the chrome-plating steel more uniform, so that the high polymer films are melted. The cause of bubbles on the surface of the coated sample may be the low melting thickness of the polymer film, and the faster coating speed reduces the heat transfer time at the film/iron interface and increases the instability of the surface temperature of the chrome-plated steel strip. On the contrary, when the coating speed is low, the increase of heat transfer time at the film/iron interface makes PET easier to melt, the number of bubbles on the surface of PCS decreases and the binding rate increases. Therefore, in order to ensure the bonding rate of the PCS coating interface and ensure an effective coating quality, the coating speed should be reduced.

Comparing sample 1, sample 4, and sample 7 , it can be found that as the temperature of the heating roller increases, the bubbles on the surface of the PCS gradually decrease, and the interface bonding rate gradually increases. Under the same laminating speed, the laminating time is the same, but as the temperature of the heating roller increases, the internal temperature of the PET film increases. Comparing the law of the influence of the coating speed on the bonding rate of the PCS interface, it can be found that the bonding rate of the PCS interface has a great relationship with the internal temperature of the PET film. The increase in the temperature of the heating roller directly leads to an increase in the internal temperature of the PET and improves the bonding rate of the PCS interface. Table 2 shows the experimental results of each binding rate test and the standard deviation of the binding rate. Figure 10 shows the interface bonding rate of the coated samples prepared under the conditions of different heating roller temperatures and filming speeds. It can be found that the influence of the heating roller temperature on the interface bonding rate is much smaller than that of the filming speed. The effect of heat transfer time on the bonding rate is much greater than the initial heating temperature of the polymer film.

Table 2. PCS interface bonding rate under different temperature and speed conditions.

\begin{tabular}{|c|c|c|c|c|c|c|c|}
\hline \multirow{2}{*}{$\begin{array}{l}\text { Sample } \\
\text { Number }\end{array}$} & \multirow{2}{*}{$\begin{array}{c}\text { Temperature } \\
\text { (K) }\end{array}$} & \multirow{2}{*}{$\begin{array}{c}\text { Laminating Speed } \\
(\mathrm{m} / \mathrm{min})\end{array}$} & \multicolumn{5}{|c|}{ Binding Rate } \\
\hline & & & 1 & 2 & 3 & $\begin{array}{c}\text { Average } \\
\text { Value (\%) }\end{array}$ & $\begin{array}{c}\text { Standard } \\
\text { Deviation (\%) }\end{array}$ \\
\hline 1 & 528 & 3 & 98.91 & 99.58 & 99.14 & 99.21 & 0.28 \\
\hline 2 & 528 & 6 & 73.2 & 84.36 & 71.94 & 76.5 & 5.58 \\
\hline 3 & 528 & 9 & 37.4 & 33.11 & 40.19 & 36.9 & 2.91 \\
\hline 4 & 533 & 3 & 99.85 & 99.89 & 99.66 & 99.8 & 0.1 \\
\hline 5 & 533 & 6 & 94.25 & 97.63 & 97.11 & 96.33 & 1.49 \\
\hline 6 & 533 & 9 & 56.33 & 48.33 & 49.24 & 51.3 & 3.57 \\
\hline 7 & 538 & 3 & 99.89 & 99.93 & 99.88 & 99.9 & 0.02 \\
\hline 8 & 538 & 6 & 99.3 & 99.67 & 96.83 & 98.6 & 1.26 \\
\hline 9 & 538 & 9 & 59.31 & 66.43 & 60.53 & 62.09 & 3.11 \\
\hline
\end{tabular}




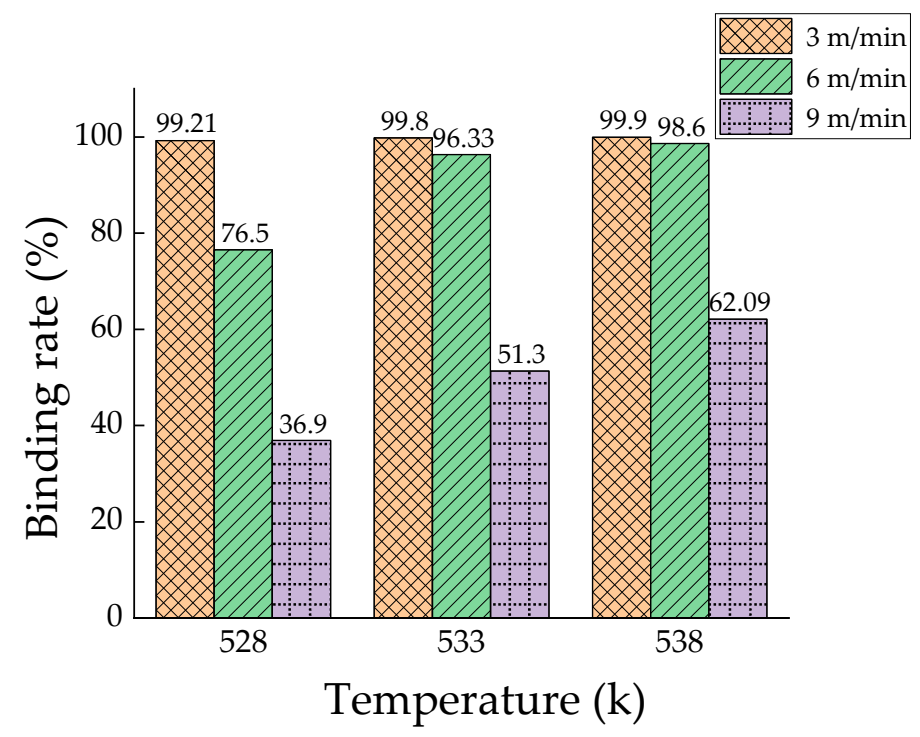

Figure 10. PCS interface bonding rate (r) under different temperature $(\mathrm{T})$ and speed $(\mathrm{v})$ conditions.

The bonding rate between the chrome-plated steel strip and the polymer film interface is intended to indicate the problem of bubble defects on the surface of the finished PCS. Through the coating test and the bonding rate detection test under different test parameters, it is found that the main factor affecting the area and number of bubbles at the film/iron bonding interface is the coating speed. This is because the decrease in the coating speed increases the film/heat transfer time at the iron interface and the heating time of the chrome-plated steel strip. The increase in the heating time of the chrome-plated steel strip makes the surface temperature of the steel strip more uniform and consistent, thereby reducing the interface bonding rate.

\subsection{Interfacial Damage and Failure Mechanisms}

The micron scratch test was performed on samples 1, 2, 3, 6, and 9. Holmberg [29] studied the deformation behavior of the diamond spherical indenter sliding on the surface of TiN coated steel through the scratch experiment and used a finite element to simulate the stress and crack formation during the scratching process. It is pointed out that the contact and deformation mechanism between the indenter and the coating can be divided into three types: ploughing, interface sliding and fracture. In the plowing stage, the indenter slides on the surface of the coating, and the coating material undergoes elastoplastic deformation to form grooves on the surface. The interface sliding stage is during the movement of the spherical indenter, the front surface of the indenter rubs against the upper surface of the coating, and the bending or stretching of the coating is accompanied by the generation and release of stress. Fracture is the separation of the coating from the base material.

The scratch morphology in Figure 11 shows that in the initial stage of pressure application, no obvious scratches are left on the surface of the sample, and the polymer film mainly undergoes elastic deformation. As the pressure of the indenter increases, the surface of the polymer film has dents and plastic deformation occurs. This stage is the plowing stage, and the polymer film has undergone elastoplastic deformation. As the pressure increases, the indenter and the film slide relatively, and the film deforms to release the stress. Then, the film breaks to release the stress again. It can be seen from the scratch morphology map in Figure 11 that there is no crack or film/iron separation on the surface of the sample before and after the scratch experiment, only a dent formed by the scratch track. It shows that the stress caused by ploughing, interface sliding, and fracture during the experiment did not affect the area outside the scratch track. It indirectly indicates that the bonding strength between the polymer film and the chrome-plated steel sheet is greater than the sum of the pressure required to cause the film to undergo plastic deformation, bending and stretching. 
From the perspective of PCS product application, scratches on the PCS surface will not cause cracks near the scratches and film/iron separation.
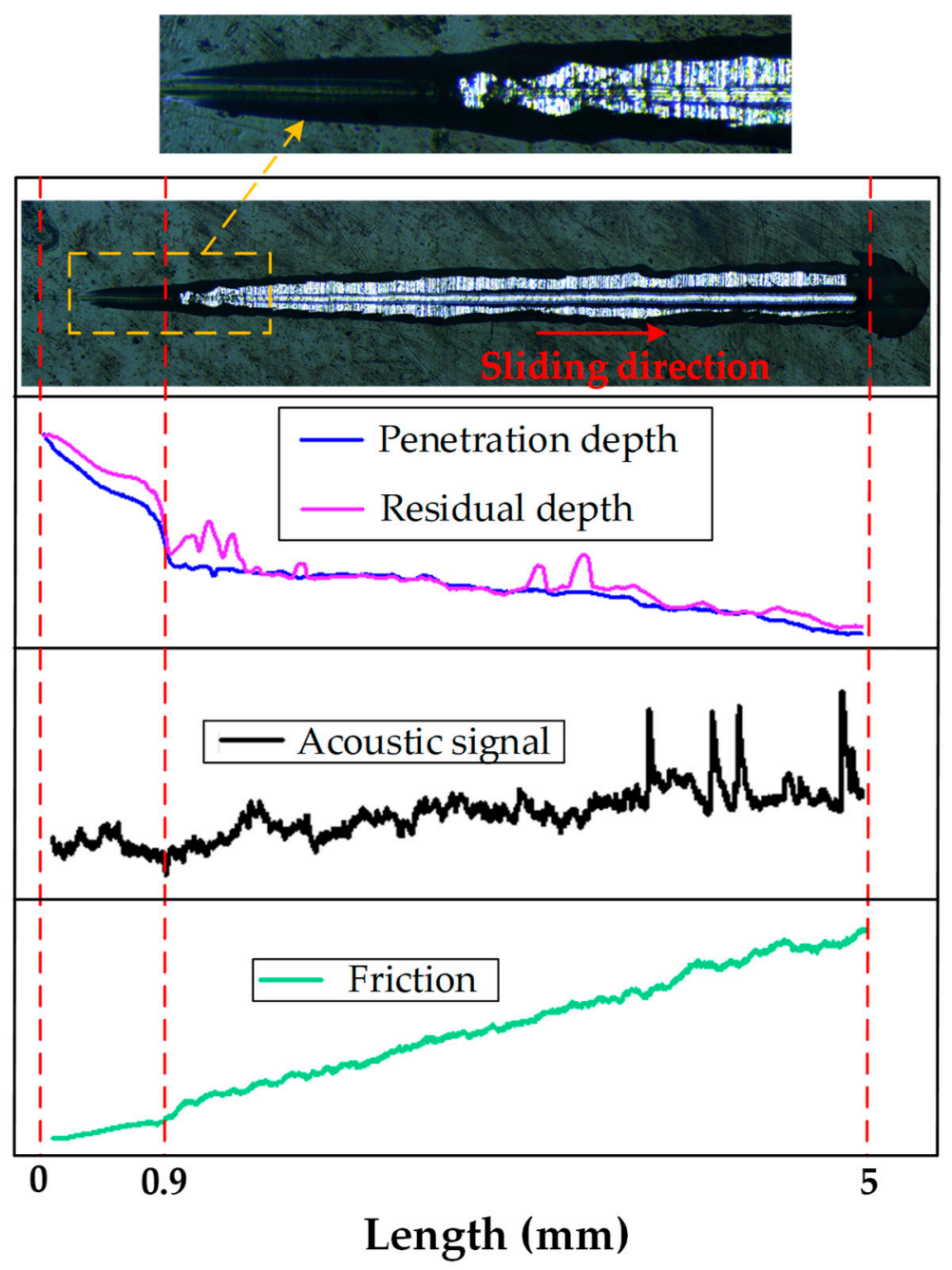

Figure 11. Schematic diagram of scratch morphology.

The penetration depth is the depth at which the indenter penetrates into the sample during the experiment, the residual depth is the depth after the material rebounds, and the difference between the penetration depth and the residual depth is the elastic recovery of the film. The difference between the penetration depth and the elastic recovery is the plastic deformation of the film.

As shown in Figure 11, when the scratch length is $0.9 \mathrm{~mm}$, the slope of the penetration depth and the residual depth has abrupt changes, and the acoustic signal and friction have also changed significantly. Combining with the scratch topography, it can be concluded that the polymer film has been completely broken. Due to the large difference between the elastic modulus of PET and TFS, the sudden gradual penetration depth indicates that the indenter has touched TFS, resulting in a decrease in penetration depth as the pressure of the indenter increases. The sudden change in friction is also caused by the difference in the coefficient of dynamic friction between the indenter and PET and TFS. The head pressure corresponding to $0.9 \mathrm{~mm}$ is approximately $2.5 \mathrm{~N}$. It can be concluded that the critical load of this coated sample is about $2.5 \mathrm{~N}$.

\subsection{Effect of Process Parameters on the Bonding Strength}

As shown in the experimental program in 2.2.2, the micro-scratch test was performed on samples 1-3, 6, and 9. Figure $12(\mathrm{a}-\mathrm{c})$ are graphs of micron scratches when the heating 
roller temperature is $528 \mathrm{~K}$ and the film speed is $3 \mathrm{~m} / \mathrm{min}, 6 \mathrm{~m} / \mathrm{min}$ and $9 \mathrm{~m} / \mathrm{min}$. The critical loads corresponding to a-c are $3.15 \mathrm{~N}, 2.88 \mathrm{~N}$, and $2.65 \mathrm{~N}$, respectively.
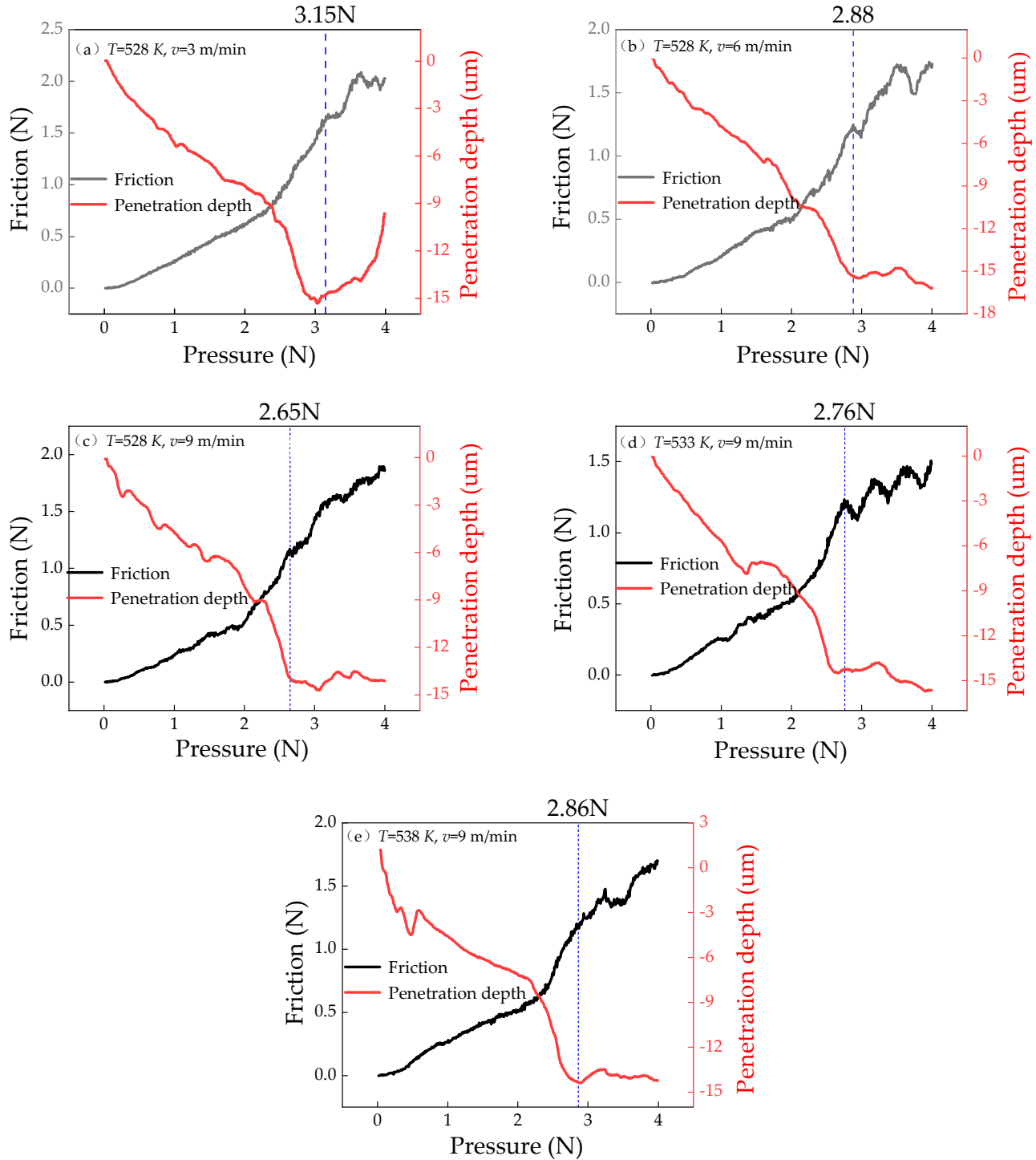

Figure 12. Critical load of sample under different process parameters $((\mathbf{a}-\mathbf{c})$ correspond to lamination speed $3 \mathrm{~m} / \mathrm{min}, 6$ $\mathrm{m} / \mathrm{min}, 9 \mathrm{~m} / \mathrm{min}$, (d,e) correspond to heating temperature $533 \mathrm{~K}, 538 \mathrm{~K})$.

As the lamination speed increases, the critical load of the sample gradually decreases, and the bonding strength of the PCS interface gradually decreases. This is because as the lamination speed increases, the contact time of the lamination zone decreases during the lamination process, which leads to a decrease in the heat transfer time at the contact interface of PET and TFS, which in turn causes the melt thickness of PET to decrease. According to the principle of the PCS roll hot melt lamination process, the high polymer film is partially melted in the thickness direction under the heating of the chrome-plated steel during the lamination process. The molten part of the substance quickly transforms into an amorphous substance to reduce the recrystallization of the molten polymer during the cooling process. Therefore, the key to improving the bonding strength of the PCS interface is to increase the thickness of the polymer amorphous layer. The increase in the filming speed reduces the melting thickness of the polymer film, resulting in a decrease in the interface bonding strength. 
Figure 12c-e are the samples under different heating temperatures and the same laminating speed. The critical loads of the coated samples correspond to the heating temperatures of $528 \mathrm{~K}, 533 \mathrm{~K}$ and $538 \mathrm{~K}$ are $2.65 \mathrm{~N}, 2.76 \mathrm{~N}$, and $2.86 \mathrm{~N}$, respectively. As the heating temperature increases, the bonding strength of the PCS interface increases. Under the same lamination speed, the heat transfer time in the laminating area is the same, but an increase of the heating temperature can directly lead to an increase of the melting thickness of the polymer film. Therefore, increasing the heating temperature can increase the bonding strength of the PCS interface.

\section{Conclusions}

The lamination temperature and lamination speed during the lamination process have an important influence on the interface bonding quality of PCS materials. As the lamination temperature increases, the PCS interface bonding rate gradually increases, and the interface bonding strength gradually increases. As the lamination speed increases, the PCS interface bonding rate gradually decreases, and the interface bonding strength gradually decreases. The PCS interface bonding rate and interface bonding strength are positively correlated. Increasing the lamination temperature and reducing the lamination speed are effective measures to improve the bonding rate and bonding strength of the PCS interface. SEM and DSC experiments revealed that the non-wetting behavior of the steel by molten PET is the cause of the bubble formation. It is speculated that the main reason is that the surface temperature of TFS is uneven during the filming process, which leads to the formation of bubbles in some areas of the polymer film not melting. Relevant research results provide guidance for enterprise production.

Author Contributions: Conceptualization, J.L., Q.Z.; methodology, B.Z.; software, J.L., and M.Y.; validation, J.L.; formal analysis, J.L.; investigation, J.L.; resources, J.L.; data curation, M.Y.; writingoriginal draft preparation, J.L., M.Y.; writing—review and editing, J.L., B.Z.; visualization, J.L., B.Z.; supervision, Q.Z.; project administration, Q.Z., J.L., and B.Z.; funding acquisition, Q.Z. All authors have read and agreed to the published version of the manuscript.

Funding: This research was funded by the National Natural Science Foundation of China (No. U1760106).

Institutional Review Board Statement: Not applicable

Informed Consent Statement: Not applicable

Data Availability Statement: All data in this work are available on request by contacting the corresponding author.

Acknowledgments: The authors are grateful for the support of the State Key Laboratory for Advanced Metals and Materials, University of Science and Technology, Beijing.

Conflicts of Interest: The authors declare no conflict of interest.

\section{References}

1. Zhang, Q.D.; Liu, J.Y.; Zhang, B.Y.; Zhang, L.Y. Advances in Theory and Technology for Laminating of Polymer-coated Steel. J. Mech. Eng. 2019, 8, 30-45. [CrossRef]

2. Yoichiro, Y.; Hiroki, I.; Toyofumi, W. Development of Laminated Tin Free Steel (TFS) 'UNIVERSAL BRITE ®' Type F for Food Cans. JFE Tech. Rep. 2007, 9, 49-53.

3. Zumelzu, E.; Cabezas, C.; Delgado, F. Performance and degradation analyses of traditional and ECCS canning tinplates in citric-citrate medium. J. Mater. Process. Technol. 2004, 152, 384-388. [CrossRef]

4. Pardo-Figuerez, M.; Lopez-Cordoba, A.; Torres-Giner, S.; Lagaron, J.M. Superhydrophobic bio-coating made by co-continuous electrospinning and electrospraying on polyethylene terephthalate films proposed as easy emptying transparent food packaging. Coatings 2018, 8, 364. [CrossRef]

5. Mousa, S.; Scheirer, N.; Kim, G.Y. Roll-bonding of metal-polymer-metal sandwich composites reinforced by glass whiskers at the interface. J. Mater. Process. Technol. 2017, 255, 463-469. [CrossRef]

6. Zumelzu, E.; Rull, F.; Boettcher, A.A. Characterization and micro- and ultra-structural analysis of PET-based Co-rolled composite electrolytic chromium coated steel (ECCS). J. Mater. Process. Tech. 2006, 173, 34-39. [CrossRef] 
7. Zumelzu, E.; Rull, F.; Boettcher, A.A. Deformation and fracture of polymer coated metal sheets: Characterisation and degradation. Surface Eng. 2006, 22, 432-438. [CrossRef]

8. Fei, S.H. Polymer Coating Effects: Study of Material Properties and Architectural Application Characteristics of Aluminum Template. Coatings 2021, 11, 240.

9. Morita, S.I.; Iwashita, H.; Tanaka, A. Effect of Contact Cooling Length between the Laminating Rolls on the Biaxial Orientation Changes of Polyester Film in the Laminating Process. J. Surf. Finish. Soc. Jpn. 2001, 52, 517-521. [CrossRef]

10. Cho, C.K.; Kim, J.D.; Cho, K.; Park, C.E.; Lee, S.W.; Ree, M. Effects of the lamination temperature on the properties of poly (ethylene terephthalate-co-isophthalate) in polyester-laminated tin-free steel can-I. Characterization of poly (ethylene terephthalate-coisophthalate). J. Adhes. Sci. Technol. 2000, 14, 1131-1143. [CrossRef]

11. Cho, C.K.; Kim, J.D.; Cho, K.; Park, C.E.; Lee, S.W.; Ree, M. Effects of the lamination temperature on the properties of poly (ethylene terephthalate-co-isophthalate) in polyester-laminated tin-free steel can-II. Adhesion mechanism of poly (ethylene terephthalate-co-isophthalate) to TFS. J. Adhes. Sci. Technol. 2000, 14, 1145-1157. [CrossRef]

12. Ruokolainen, R.B.; Sigler, D.R. The Effect of Adhesion and Tensile Properties on the Formability of Laminated Steels. J. Mater. Eng. Perform. 2008, 17, 330-339. [CrossRef]

13. Braasch, D.A.; Gillis, M.; Pramanik, M.; Ferguson, R.C. Detection of in Situ Early Corrosion on Polymer-Coated Metal Substrates. ACS Appl. Mater. 2019, 11, 37193-37208. [CrossRef] [PubMed]

14. Zumelzu, E.; Wehrhahn, M.J.; Rull, F.; Pesenti, H.; Munoz, O.; Ugarte, R. Evaluation of salmon adhesion on PET-metal interface by ATR, FT-IR, and raman spectroscopy. J. Spectrosc. 2015, 2015, 1-7. [CrossRef]

15. Iwashita, H.; Morita, S.I.; Tanaka, A. Development of Amorphous Layer of Biaxially Oriented Polyester Film on Laminated Steel in the Laminating Process. Tetsu-to-Hagane 2001, 87, 175-182. [CrossRef]

16. Liu, J.; Zhang, Q.; Geng, L.; Zhang, B.; Zhang, L. Study on evolution law of lateral thickness difference of polymer-coated steel in laminating process. Mater. Today Proc. 2020, 33, 2059-2065. [CrossRef]

17. Terauchi, F.; Iwashita, H.; Tanaka, A.; Morita, S. Effect of Annealing Temperature on Adhesion of Polyester Film to Electrolytically Chromium Coated Steel. Tetsu-to-Hagane 1999, 85, 236-240. [CrossRef]

18. Matsubayashi, H. Metal Can using Polyester Film Laminated ECCS (Electrolytic chromium/chromium oxide-coated steel). Zairyo Kankyo 2002, 51, 299-304. [CrossRef]

19. Ranjbar, N.; Talebian, S.; Mehrali, M.; Kuenzel, C.; Metselaar, H.S.C.; Jumaat, M.Z. Mechanisms of interfacial bond in steel and polypropylene fiber reinforced geopolymer composites. Compos. Sci. Technol. 2016, 122, 73-81. [CrossRef]

20. Lindner, M.; Rodler, N.; Jesdinszki, M.; Schmid, M.; Sängerlaub, S. Surface energy of corona treated PP, PE and PET films, its alteration as function of storage time and the effect of various corona dosages on their bond strength after lamination. J. Appl. Polym. Sci. 2018, 135, 45842. [CrossRef]

21. Yang, L.; Chen, J.; Guo, Y.; Zhang, Z. Surface modification of a biomedical polyethylene terephthalate (PET) by air plasma. Appl. Surface Sci. 2009, 255, 4446-4451. [CrossRef]

22. Jiang, Z.; Jiang, Z.J. Plasma techniques for the fabrication of polymer electrolyte membranes for fuel cells. J. Membr. Sci. 2014, 456, 85-106. [CrossRef]

23. Komai, M.; Taniguchi, A.; Shimizu, N.; Shimizu, K.; Tanaka, A. Effects of composition and microstructure of hydrated chromium oxide on adhesive property of PET/I film laminated TFS. Tetsu-to-Hagane 2009, 83, 377-382. [CrossRef]

24. Suzuki, T.; Iwasa, H.; Yamashita, M. The Mechanism of Wet Adhesion of the PET-laminated Steel Sheet. Tetsu-to-Hagane 2003, 89, 142-148. [CrossRef]

25. Zumelzu, E.; Angulo, C.; Cabezas, C.; Ugarte, R. Characterisation of nanometric chromium coatings in metal-polymer composites. Surface Eng. 2013, 29, 620-626. [CrossRef]

26. Liu, J.; Zhang, Q.; Zhang, B.; Yu, M. The Bonding Mechanism of the Micro-Interface of Polymer Coated Steel. Polymers 2020, 12, 3052. [CrossRef] [PubMed]

27. Manasoglu, G.; Elen, R.; Kanik, M.; Ulcay, Y. An Investigation on the Thermal and Solar Properties of Graphene-Coated Polyester Fabrics. Coatings 2021, 11, 125. [CrossRef]

28. Ding, L.; Xie, L.; Cao, J.; Bai, Y. Crystallization behavior of poly (ethylene terephthalate-co-neopentyl terephthalate-co-ethylene isophthalate-co-neopentyl isophthalate) copolyester and its application in laminated tin-free steel. J. Appl. Polym. Sci. 2015, 42308. [CrossRef]

29. Holmberg, K.; Laukkanen, A.; Ronkainen, H.; Wallin, K.; Varjus, S. A model for stresses, crack generation and fracture toughness calculation in scratched TiN-coated steel surfaces. Wear 2003, 254, 278-291. [CrossRef] 